\title{
The Year in Review: Economics at the Antitrust Division, 2009-2010
}

\author{
Ken Heyer • Carl Shapiro
}

Published online: 7 December 2010

(C) The Author(s) 2010. This article is published with open access at Springerlink.com

\begin{abstract}
This paper covers the activities of the Economic Analysis Group of the Antitrust Division, U.S. Department of Justice, during 2009-2010. It describes the economic analysis undertaken by EAG in several important investigations and other activities as an advocate for competition.
\end{abstract}

Keywords Antitrust · Competition policy · Mergers

\section{Introduction}

The past year has been an active and exciting one for economists in the Economic Analysis Group (EAG) of the Antitrust Division, U.S. Department of Justice (DOJ). As in years past, a substantial share of their efforts were devoted to reviewing proposed mergers and acquisitions. The economic analyses that were performed in several of these are described in this article. In addition, EAG has been actively involved in a variety of competition advocacy efforts, including the presentation of the Department of Justice's views in regulatory filings with sister agencies and in the preparation of amicus briefs filed with the Supreme Court. EAG economists also continue to provide training, both domestically and in international settings, and to engage in substantial individual research, the results of which are often presented at academic conferences and/or published in academic journals and other publications.

The views contained herein are solely those of the authors and do not necessarily represent those of the U.S. Department of Justice.

K. Heyer $(\varangle) \cdot$ C. Shapiro

Competition Policy Section and Deputy Assistant Attorney General for Economics, Antitrust Division, United States Department of Justice, Washington, DC, USA

e-mail: ken.heyer@usdoj.gov 
In this review article we describe a number of these activities, focusing especially on ones that raised interesting or subtle economic issues. We discuss a number of specific merger investigations, including some — such as Ticketmaster/Live Nation and Baker Hughes/BJ Services - that culminated in consent decrees and substantial divestitures of assets, and one-Dean Foods/Foremost Dairies - that is the subject of ongoing litigation. In the civil non-merger area we discuss the Division's investigation of a set of agreements in the high-tech industry that had been limiting the ways in which several prominent firms were competing for employees. In the competition advocacy arena we describe the Division's analysis of a proposal before the Department of Transportation to permit Delta and US Airways to swap slot holdings at LaGuardia and Reagan National airports.

We provide also a discussion of the economic analysis that was employed by the Division in an interesting matter in the electricity industry - the "Keyspan Swap"-in which the Division proposed a settlement that required the disgorgement of profits.

In our discussion of these matters, we are unable-due to confidentiality considerations as well as space limitations - to present in its entirety the relevant economic issues and arguments or the Division's analysis of the available evidence. Nor do we attempt to provide a complete explanation for why each matter was decided as it was. Rather, in the interests of focusing on the interesting economics at issue, we highlight only the salient facts, omitting some details, without (in our view) doing injustice to the critical economic arguments in play in these cases. As in articles from previous years, we hold to the view that the precise facts uncovered in any given investigation are of far less interest to most readers than is a discussion of the analytical work that was conducted by the Division' $=$ s economists based on those facts.

Economists at the Division continued to turn out a considerable amount of original research in the past year in the form of EAG Discussion Papers or articles in scholarly journals. Much of this research was based on casework, but a significant fraction dealt with antitrust, applied microeconomics, and econometrics more generally. Examples include Essays in Consumer Welfare and Competition Policy (Werden 2009), Competition Among Spatially Differentiated Firms: An Empirical Model with an Application to Cement (Miller and Osborne 2010), and Filling Out the Instrument Set in Mixed Logit Demand Systems for Aggregate Data (Romeo 2010). ${ }^{1}$

\section{Mergers}

\subsection{Baker Hughes/BJ Services}

On April 27, 2010, the Department of Justice filed a Complaint ${ }^{2}$ in the District Court of the District of Columbia challenging the proposed merger of Baker Hughes Incorporated ("Baker Hughes") and BJ Services Company ("BJ Services"). At the same

\footnotetext{
${ }^{1}$ For a complete list of EAG Discussion papers, see http://www.justice.gov/atr/public/eag/discussion papers.htm.

2 See Complaint,U.S. v. Baker Hughes Inc. and BJ Services (http://www.justice.gov/atr/cases/f258100/ 258179.htm).
} 
time, the Department filed a proposed settlement requiring divestitures and other terms and conditions that would eliminate its concerns over the competitive effects of the merger.

Baker Hughes and BJ Services are two of only four companies that operate specially equipped vessels that provide oil and gas companies with pumping services ("vessel stimulation services") in the U.S. Gulf of Mexico. These vessel stimulation services are used in the vast majority of offshore wells in the Gulf. Our investigation confirmed that the provision of vessel stimulation services in the Gulf constituted a relevant product market because oil and gas customers would not markedly reduce their consumption of this service-which represented only a small fraction of their total cost of production-in response to even a significant increase in its price. Further, because suppliers can readily price their services differently as a function of the location of the job, services provided in the Gulf comprised the relevant geographic component of the market.

We concluded that the competitive concerns ${ }^{3}$ raised in the vessel stimulation services market were not inextricably linked to the realization of significant mergerspecific efficiencies, ${ }^{4}$ and that neither entry nor the threat of entry, nor repositioning, were likely to prevent a post-merger exercise of greater market power. ${ }^{5}$

The primary, and most controversial, economic issues addressed in this investigation related to our competitive effects analysis. The Division concluded that the merging parties earned very substantial price-variable cost margins on their provision of vessel stimulation services. Therefore, merely as a matter of arithmetic, a unilateral attempt by the merged firm to raise price by a small amount would be unprofitable even if only a relatively small fraction of these sales would be lost. One key issue, therefore, was whether the fraction of sales likely to be lost would be at least that large. A closely related issue was the extent to which the sales lost by one of the merging firms from raising its pre-merger price would be recaptured as greater business by the other merging firm. Absent any such internalization of lost sales, there would be no difference between the incentive for the merged firm unilaterally to raise price post-merger and the incentives of the individual firms to do so pre-merger.

Baker Hughes and BJ Services were close competitors. During the past two years they ranked first and second in terms of total expenditures on vessel stimulation services by many customers, and they shared many of the same characteristics. For similar types of jobs they charged similar prices, operated in the same water depths, and served customers at many of the same geological locations. This suggested that their services, while differentiated, were relatively close substitutes for one another.

\footnotetext{
3 See Competitive Impact Statement, U.S. v. Baker Hughes Inc. and BJ Services (http://www.justice.gov/ atr/cases/f258200/258203.htm).

4 The merger combined a wide range of assets that were used to provide a variety of different services, and in some affected markets synergies may have been likely. The targeted divestitures sought by the Division addressed the Division's competitive concerns without sacrificing these possible efficiencies.

5 Timely entry was unlikely, in part because under a federal law known as the Jones Act, stimulation service vessels are prohibited from operating in the Gulf unless they have been built in the United States, bear a United States flag, and are staffed with a United States crew. Only a limited number of such vessels worldwide are Jones Act compliant, and all are operated by the same four firms that currently compete in the Gulf.
} 
Combined with the fact that only two other firms competed in the market and demand was highly inelastic, this evidence led us to conclude that the diversion ratios between the services offered by the two firms were significant. ${ }^{6}$

Combined with the relatively high pre-merger margins, this led us to conclude that the merger would generate significant upward pricing pressure on the services offered by the two firms. More specifically, we concluded that the gross upward pricing pressure index (GUPPI) for the services offered by the two firms was significant. The GUPPI from Product 1 to Product 2 is defined as $\frac{D_{12}\left(P_{2}-C_{2}\right)}{P_{1}}$, where $D_{12}$ is the diversion ratio from Product 1 to Product 2 and the other variables represent prices and marginal costs. ${ }^{7}$

Furthermore, there were significant capacity limitations on the ability of the remaining two competitors to capture business from the merged firm in response to a postmerger price increase. Drilling and completing a well is very costly, particularly in deepwater, and demand for vessel stimulation services is extremely time-sensitive. Daily costs for drilling rigs and other assets may be $\$ 1$ million or more for wells in deepwater. These assets remain at the drilling site while vessel stimulation services are performed and throughout the completion process. If a vessel is not available precisely when its services are demanded, the customer will incur very high costs while waiting for it to arrive.

Firms in the market face intermittent or recurring capacity constraints, and although the vessels of each firm seemingly had significant unutilized capacity "on average," (i.e., they were performing jobs during only a portion of each month), this did not mean that in the event of a post-merger price increase by a merged Baker Hughes/BJ Services they would be available to provide competitive discipline. The time-sensitive and highly inelastic nature of demand in this market is such that when customers are willing to pay a great deal for a vessel's services, the vessels of one or more firms may happen to be busy. By combining the assets of two of only four competitors (each of whom operate only two vessels), the merger therefore increased the likelihood that the residual demand curve facing the merged firm would at times be highly inelastic, making it profitable for the merged firm to bid perhaps significantly higher.

The Division negotiated with the merging parties a consent decree that required that two vessels, along with other assorted rights and assets, be divested to a third party that is willing and able to replace the competition that was otherwise eliminated by the merger.

\subsection{Ticketmaster/Live Nation}

This merger combined Ticketmaster, the country's dominant ticketing service provider for major concert venues, with Live Nation, the country's largest concert promoter.

\footnotetext{
6 The diversion ratio from one product to another is defined as the fraction of unit sales lost by the first product in response to a price increase on that product that would be diverted to the other.

7 Shapiro (2010) explains the relationship between GUPPI and the "value of diverted sales" measure of upward pricing pressure that is described in Sect. 6.1 of the recently revised Horizontal Merger Guidelines. The Guidelines measure the value of diverted sales in proportion to the lost revenues attributable to the reduction in unit sales resulting from the price increase. See also Shapiro (2010).
} 
These two industry giants had for some years provided complementary, rather than competing, services. In 2007, however, after having used Ticketmaster for much of its ticketing requirements, Live Nation announced that it would not renew its contract with Ticketmaster and would begin competing with Ticketmaster in the primary ticketing business. In February 2009, the parties announced that they would merge their operations, and eleven months later the Department of Justice filed a Complaint challenging the merger under Sect. 7 of the Clayton Act. ${ }^{8}$ Simultaneously with filing its Complaint, a Consent Decree was filed with the Court. Under its terms, the merger would go forward following the parties' divestiture of certain assets and agreement to refrain in the future from certain forms of anticompetitive conduct.

One of the key issues in the investigation involved product market definition: whether and why antitrust markets might be narrower than "all ticketing services to all venues." Another key question was whether and why, among existing ticketing firms, Live Nation was in an important economic sense a uniquely well-positioned threat to Ticketmaster's dominant position. A third key question was whether, even in the absence of new entry by Live Nation, Ticketmaster's long-time dominance was being seriously and sufficiently eroded by other economic forces, especially by greater use of the Internet for ticketing.

On the issue of product market definition, Ticketmaster has long provided ticketing services for many types of live performances. And, for some types of live performances - including those at many smaller venues, but also at some large and predominantly sporting facilities_-alternatives to Ticketmaster do compete effectively and capture a significant share of available business. A question therefore arose as to whether the availability of alternatives for certain of Ticketmaster's customers might prevent the merged Ticketmaster-plus-Live Nation from exercising significant market power over other customers-especially the large concert venues for whom alternatives to Ticketmaster (and, eventually, Live Nation) were decidedly inferior and Ticketmaster's share of business was extremely high.

The competitive constraint provided by good economic alternatives for some types of customers was found not to provide protection for those that were most desirous of Ticketmaster's services. This is because price discrimination was quite feasible in this industry. ${ }^{9}$ Bidding for customer contracts permitted the setting of different terms for different customers, and Ticketmaster was generally very knowledgeable about the types of customers with less elastic demand for its services. These customers typically were the large concert venues: customers whose products required ticketing technology capable of reliably handling dramatic short-term surges in demand. Firms other than Ticketmaster typically did not have the technology, expertise, or track record of successful performance to be able to compete effectively for these customers. Ticketmaster's ability to identify and target the large concert venues, along with the inability of customers (or intermediaries) to arbitrage such services, resulted in there being a

\footnotetext{
8 See Complaint, U.S. et al. v. Ticketmaster and Live Nation (http://www.justice.gov/atr/cases/f254500/ 254552.htm).

9 See U.S. Department of Justice and Federal Trade Commission, Horizontal Merger Guidelines Sect. 3: Targeted Customers and Price Discrimination (http://www.justice.gov/atr/public/guidelines/hmg-2010. html).
} 
large number of customers that were vulnerable to a significant post-merger exercise of market power. Put differently, the Division concluded that there was a relevant price discrimination market for ticketing services provided to major concert venues.

Given that large concert venues demanded services for which Ticketmaster commanded substantial market power, what was it that made Live Nation so special? Live music entertainment is composed of multiple components - the performers, their manager/agents, promotion services, venue operation, and ticketing. As the largest single provider of services that were complementary to ticketing for major concert venues - in particular, concert promotion - and as the owner of a number of major concert venues, Live Nation had an unusually strong incentive to make the investments necessary to create competition in that market. Successful entry by Live Nation would potentially be profitable to Live Nation not simply because it could hope to capture (from Ticketmaster) some of the profits from being in the ticketing business. Successful entry by Live Nation would also, by lowering the cost of services to itself, enable Live Nation to capture a greater share of the "live performance pie" through greater profit in its extensive promotion and venue operation businesses. Indeed, it was the inability of these two live concert industry giants to reach acceptable terms under which Ticketmaster would continue providing ticketing services for Live Nation that induced Live Nation to announce its entry into the ticketing business.

The size and scope of Live Nation's complementary businesses afforded it other advantages as well. Live Nation believed that its prominence in promotions would give it immediate credibility in primary ticketing, and by providing considerable ticketing services at its own venues it expected to demonstrate reliability, develop quickly a track record, and be well-positioned to compete head-to-head against Ticketmaster for the business of large venues operated by third parties. Indeed, the evidence indicated that Live Nation had embarked on this strategy shortly before reaching its merger agreement with Ticketmaster.

The Division saw strong indications that, had the merger gone through as originally proposed, competition would have been affected adversely. ${ }^{10}$ An independent Live Nation would have put downward pressure on the price of ticketing services, spurred innovation in ticketing services and otherwise enhanced service quality and product variety; these effects would have been muted by the merger. However, predicting the effects of the merger was complicated by the fact that the merger was announced prior to Live Nation's having established itself as a fully effective competitor in providing ticketing services to major concert venues other than Live Nation's own venues. The case thus raised the question of whether a vertically integrated firm (Live Nation, a venue owner integrating into ticketing services) could compete effectively in the "merchant market" (provision of ticketing services to venues owned and operated by others).

Furthermore, the merging parties claimed that successful entry into ticketing by Live Nation was unnecessary to provide effective competition for Ticketmaster, because broader economic forces, including greater use of the Internet, were eliminating Ticketmaster's historical market power even in the absence of new entry by Live Nation. It

10 See Competitive Impact Statement, U.S. et al. v. Ticketmaster and Live Nation (http://www.justice.gov/ atr/cases/f254500/254544.htm). 
appeared to be the case, for example, that over the recent past—prior to Live Nation's announced entry-service fees on ticketing had been falling. One might perhaps infer that this evidenced substantial new competition even without entry by Live Nation.

A closer examination of the evidence, however, suggested otherwise. Incremental costs to Ticketmaster of distributing tickets had been falling sharply during this time, largely as a result of increased purchases by consumers of tickets through the Internet (in contrast with sales at kiosks or over the telephone). Lower incremental costs, of course, provide an economic incentive for even a monopolist to reduce the price that it charges to its customers. Hence, lower ticketing fees, or even a smaller share of total ticketing costs that would go to the supplier of ticketing services, would be consistent with Ticketmaster having retained substantial market power. And indeed, the evidence indicated that ticketing fees that were retained by Ticketmaster had not fallen even though its distribution cost had been declining.

Ultimately, the Division negotiated with the parties a package of substantial relief measures that permitted Ticketmaster and Live Nation to consummate their merger. These included the divestiture of certain of Ticketmaster's ticketing assets and licensing of the rights to use Ticketmaster ticketing technology to firms that had the ability and incentive to replace the competition that was otherwise eliminated by the merger. The remedy also imposed behavioral conditions to prohibit the merged firm from impeding ticketing competition by conditioning the supply of content controlled by the merged firm on a venue's acceptance of the merged firm as its ticketing services provider.

\subsection{Dean Foods/Foremost}

On January 22, 2010, the Department of Justice filed a Complaint that challenged the acquisition by Dean Foods of the Consumer Products Division of Foremost Farms USA, a transaction that had been consummated on April 1, 2009. ${ }^{11}$ The Antitrust Division's economic analysis of the transaction, which is currently in active litigation, applies and illustrates some of the practices and principles laid out in Horizontal Merger Guidelines issued by the DOJ and the Federal Trade Commission (FTC). In particular, it illustrates the application of theory and evidence to issues of market definition - here, price discrimination markets - and to the analysis of possible post-merger coordinated and unilateral effects.

Dean and Foremost are two of a small number of dairy processors that supply customers in a number of geographic regions in Wisconsin, Illinois and Michigan. The Division's analysis determined that Dean's acquisition of Foremost's two dairy processing plants was anti-competitive in the supply of school milk to a significant number of school districts in the state of Wisconsin, and in the supply of fluid milk to purchasers in Wisconsin, the Upper Peninsula (UP) of Michigan, and northeastern Illinois.

School milk markets are, for sound economic reasons, properly viewed as price discrimination markets. The basic prerequisites for successful price discrimination by

11 See Complaint, U.S. et al. v. Dean Foods (http://www.justice.gov/atr/cases/f254400/254455.htm). 
a hypothetical monopoly supplier-the ability to identify customers and price differentially to them, combined with an inability of at-risk customers to protect themselves via arbitrage - are satisfied. And in this particular matter, the post-merger monopoly is not merely hypothetical, it is actual. There are numerous school districts, particularly in northeastern Wisconsin and the western UP, that Dean and Foremost were best situated to serve. For many of these school districts, Dean and Foremost were the only bidders in recent years, and for others one of them had been the only bidder, with the other being the next-lowest-cost supplier because of factors such as distance from the processing plant or the nearby presence of an established distribution network.

The demand for school milk (milk that is packaged and distributed for sale to school districts, typically in half-pint containers) is highly inelastic. The U.S. Department of Agriculture (USDA) sponsors several programs to reimburse schools for meals that are served to students from lower-income families. To qualify, schools must offer milk to every student, regardless of family income. Schools will not substitute other products for school milk even at substantially higher milk prices because they would lose their federal meal reimbursement. As additional evidence of school milk's being a relevant product market, the U.S. Department of Justice has on multiple occasions and across multiple geographic regions in the past prosecuted explicit collusion in the pricing of school milk. ${ }^{12}$ A group of firms is not likely to collude if the demand facing them collectively is sufficiently elastic that any significant price increase above competitive levels would not be collectively profitable.

Regarding the sale of fluid milk to non-school purchasers, theory and available evidence motivated significant concern over the likelihood that the merger would generate anticompetitive effects. As an initial matter, consumer demand for fluid milk is relatively inelastic. And, because demand by retailers and other distributors of fluid milk is derived from consumer demand, demand by distributors is inelastic as well.

Milk processors charge different prices to different purchasers for the same product based on a variety of factors, including transportation costs, service costs, and capacity utilization. Dean and Foremost often competed head-to-head to win fluid milk contracts because they were the nearest fluid milk processors to many of the purchasers in the relevant geographic market. Proximity is an important consideration in fluid milk pricing because fluid milk has a limited shelf life and is costly to transport. In addition, Foremost had substantial excess capacity and different pricing incentives than did Dean. Before Dean acquired its plants, Foremost had been pricing aggressively to secure new business, and Dean's internal memoranda referred to Foremost as an "irrational local competitor" whose quest for greater plant utilization threatened existing margins.

In addition to concerns over unilateral anticompetitive effects, the Division concluded that the acquisition would facilitate anticompetitive coordination. As explained in the 2010 Horizontal Merger Guidelines, ${ }^{13}$ a merger raises coordinated effects concerns when the following conditions are satisfied (1) the merger results in a significant increase in concentration and concentration post-merger is high, (2) conditions are

\footnotetext{
12 See, for example, Porter and Zona (2009).

13 See U.S. Department of Justice and Federal Trade Commission, Horizontal Merger Guidelines Sect. 7: Coordinated Effects (http://www.justice.gov/atr/public/guidelines/hmg-2010.html).
} 
such that the market appears vulnerable to coordinated conduct, and (3) the merger increases vulnerability by, for example, making coordination more likely and/or more effective.

Foremost's differing pricing incentives resulting from, in particular, its low capacity utilization, impeded the ability of Dean and the few other significant suppliers in the region to earn higher margins by coordinating their behavior. In one recent bidding event, for example, Dean had refused to bid aggressively for a significant account handled by Kemps, a large competitor, because it feared retaliation. Foremost was not similarly deterred, presumably calculating that its upside from stealing a large account with an aggressive bid was greater than the cost it might incur from retaliation.

With the elimination of Foremost, fluid milk purchasers in many areas of the relevant geographic market would have only two or three significant suppliers of fluid milk. These remaining firms, generally characterized in Dean's internal documents as "good competitors," were believed not to possess the same "irrational" pricing incentives as those already evidenced by Foremost. In Wisconsin, for example, Dean and its next-largest competitor (Kemps) now account for more than 80 percent of sales.

\section{Non-Merger Matters}

\subsection{The KeySpan Swap ${ }^{14}$}

\subsubsection{Institutional Background}

On February 22, 2010, the United States filed suit against KeySpan Corporation ("KeySpan") to remedy a violation of Sect. 1 of the Sherman Act. ${ }^{15}$ Economic analysis of this matter, including the Division's decision to seek disgorgement of illegally obtained profits, illustrates at least two important economic principles that are relevant to sound competition policy. One is that conduct short of merger or an explicit agreement not to compete can, by altering a firm's incentives, harm competition. Another is the role that disgorgement can play in appropriate circumstances to promote competition by altering the incentives of firms to violate the antitrust laws in the future.

Because transmission constraints limit the amount of energy that can be imported into the New York City area from the power grid, the New York Independent System Operator (NYISO) requires retail providers of electricity to New York City consumers to purchase 80 percent of their capacity from generators in that region. The New York City installed capacity market was highly concentrated during the relevant period, with Astoria, KeySpan, and one other firm (NRG Energy, Inc.) controlling a substantial portion of the market's generating capacity. These three firms were designated by the Federal Energy Regulatory Commission as "pivotal suppliers," meaning that at least some of each of these suppliers' output was required to satisfy demand. The three

\footnotetext{
14 Shapiro was recused on this matter and is not a co-author of this section.

15 See Complaint, U.S. v. Keyspan Corp (http://www.justice.gov/atr/cases/f255500/255507.htm), and Competitive Impact Statement, U.S. v. Keyspan Corp (http://www.justice.gov/atr/cases/f255500/255578. htm).
} 
firms were subject to bid and price caps, meaning that they could not bid to supply capacity at a price higher than their price cap. ${ }^{16}$ KeySpan's cap was the highest.

The price for installed capacity has been set by auctions that are administered by the NYISO. Capacity suppliers offer price and quantity bids, and the resulting "supply curve" is compared to the amount of demand. The offering price of the last bid needed to meet the requisite demand establishes the market price for all capacity sold into that auction. Capacity that is bid at higher than the market clearing price goes unsold, as does any excess capacity bid at what becomes the market price.

\subsubsection{The Conduct}

From June 2003 through December 2005, almost all installed capacity in the market was needed to meet demand. Under these conditions, KeySpan could sell almost all of its capacity into the market, even while bidding the highest price permitted by its cap. KeySpan did so, and the market cleared at the cap price with only a small fraction of KeySpan's capacity remaining unsold.

KeySpan anticipated that these favorable market conditions were likely to end in 2006, as a result of the entry into the market of a significant amount of additional generating capacity. Bidding its cap would place KeySpan at significant risk that much of its capacity would not be sold. Alternatively, KeySpan could compete by bidding more of its capacity at lower prices, but this too would have involved KeySpan's earning lower prices on capacity sold.

KeySpan considered a variety of responses to the changing market conditions, including purchasing Astoria's generating assets, which were up for sale. While this would have solved KeySpan's problem, it would clearly have raised market power concerns on the part of regulators and was not pursued. Instead of purchasing the Astoria assets, KeySpan acquired a financial interest in Astoria's capacity.

KeySpan did not approach Astoria directly. Rather, it sought a counterparty to enter into a financial agreement that provided KeySpan with payments as a function of the market clearing price for an amount of capacity essentially equivalent to what Astoria owned. KeySpan recognized that the counterparty would be simultaneously entering into a hedging agreement with Astoria to offset its payments to KeySpan. Indeed, the financial services company serving as the counterparty informed KeySpan that their agreement was contingent on the counterparty's entering into an offsetting agreement (the "Astoria Hedge") with the owner of the Astoria generating assets.

On or about January 9, 2006, KeySpan and the financial services company finalized the terms of the KeySpan Swap. On or about that same date, the financial services company and Astoria finalized terms of the Astoria Hedge. ${ }^{17}$ The net effect of these two transactions was, economically, as if KeySpan had purchased capacity directly from Astoria itself. Under the agreement, if the market price were above $\$ 7.57$ per

\footnotetext{
16 To bid in the capacity market is not equivalent to bidding in the day-ahead energy market. To bid in the energy market is to bid to supply generation output to meet demand in electricity. Capacity markets, on the other hand, are constructed to ensure that there is sufficient generation capacity that is available in a specific area. 17 Astoria could have self-financed, though it found more attractive the hedge contract which facilitated third party financing.
} 
kW-month, KeySpan would be paid the difference between the market price and \$7.57 times 1800 megawatts. Unsold KeySpan capacity at a high market price would continue to be a cost of bidding high; however this disincentive to bid high would now be countered by the guaranteed payments to KeySpan produced by the Swap.

The clear tendency of the KeySpan Swap was to alter KeySpan's bidding behavior in the NYC Capacity Market auctions. Without the swap, KeySpan would more likely have chosen from a range of potentially profitable competitive strategies in response to the entry of new capacity. Had it done so, the price of capacity would have declined. The swap, however, effectively eliminated KeySpan's incentive to compete for sales. By adding revenues from Astoria's capacity to KeySpan's own, the KeySpan Swap made bidding the cap KeySpan's most profitable strategy regardless of its rivals' bids.

The Swap effectively eliminated KeySpan's incentive to compete for sales in the same way that a purchase of Astoria or a direct agreement between KeySpan and Astoria would have accomplished. And after the KeySpan Swap went into effect, KeySpan consistently bid its capacity into the capacity auctions at its cap even though a significant portion of its capacity went unsold. Despite the addition of significant new generating capacity in New York City, the market price of capacity did not decline.

\subsubsection{Remedy}

The proposed Final Judgment requires KeySpan to disgorge \$12 million of profits that were gained as a result of its unlawful agreement restraining trade. Prior to this matter, the Antitrust Division had not previously sought disgorgement as a remedy under the Sherman Act, ${ }^{18}$ although district courts do have the authority to order such equitable relief.

The Division deemed disgorgement appropriate in this case to protect the public interest by depriving KeySpan of the fruits of its ill-gotten gains and, perhaps more importantly from an economic perspective, to deter KeySpan and others from engaging in similar anticompetitive conduct in the future. Permitting firms to profit by violating the antitrust laws provides them with a greater incentive to do so than if they are forced to disgorge ill-gotten gains. Policies that increase the likelihood of illegal agreements' having adverse financial consequences to the perpetrators - even if only in the form of disgorging ill-gotten gains (rather than a perhaps more aggressive approach of imposing fines or other penalties) would seem to be, all else equal, moving in the direction of a more optimal deterrence policy.

\subsection{No Poach Agreements Between High Technology Firms ${ }^{19}$}

On September 24, 2010, the Department of Justice announced that it had reached a settlement with six high technology companies-Adobe Systems Inc., Apple Inc.,

\footnotetext{
18 The Division does, of course, regularly seek and achieve sizable fines as criminal penalties in price-fixing prosecutions.

19 See Complaint, U.S. v. Adobe et al. (http://www.justice.gov/atr/cases/f262600/262654.htm), and Competitive Impact Statement, U.S. v. Adobe et al. (http://www.justice.gov/atr/cases/f262600/262650.htm.
} 
Google Inc., Intel Corp., Intuit Inc., and Pixar-that prevents them from entering into no-solicitation agreements for employees. The Department said that the agreements eliminated a significant form of competition to attract highly skilled employees, and overall diminished competition to the detriment of affected employees who were likely deprived of competitively important information and access to better job opportunities. Together with a civil antitrust complaint, the Antitrust Division filed the proposed settlement. If approved by the court, the settlement would resolve the lawsuit.

Following a lengthy investigation, the Antitrust Division determined that a number of bilateral agreements that were entered into by the defendants blunted competition for workers and were not ancillary to legitimate business purposes. The defendants in this matter are high-technology firms that compete against one another for specialized computer engineering talent. The labor market for talent demanded by these firms is characterized by considerable expertise and specialization. The agreements at issue did not preclude all forms of competition between the defendants for employees. The agreements were to refrain from competing through one particular method: "cold calling" another firm's current employees.

Although the firms employ a wide variety of recruiting techniques, direct solicitation of another firm's employees can be a particularly effective method. Cold calling by interested employers to particularly attractive candidates is a common technique in other industries and, indeed, is a practice engaged in by other firms in the high-tech labor market. It can be both an important complement to, and substitute for, other recruiting methods. ${ }^{20}$

Agreements of this type can in principle harm employees by lowering the salaries and benefits that they might otherwise have commanded, whether or not they ultimately chose to remain with their current employer. They can also deprive employees of potentially more attractive job opportunities and lead to a misallocation of labor resources in the economy. Competition, whether in the product market or in the labor market, tends to allocate resources to their most highly valued uses. Agreements that limit competition for employees can undermine this competitive process and result in employees' staying at firms that do not best utilize their scarce and specialized skills.

One can imagine defenses for agreements not to compete. In light of the facts in this case, these were deemed by the government to be without merit, as explained below.

\subsubsection{No Harm, No Foul?}

One might argue that the agreements actually had no effect and therefore ought to be permitted. As noted above, many other forms of competition for talent were permitted, and these were in fact employed effectively. Employees not uncommonly switched jobs across companies, even between companies who had entered into the "no cold calling" agreements. Establishing a significant overall effect of the agreements on the

\footnotetext{
20 Antitrust cases involving agreements directed at workers are far less common than ones dealing with agreements among businesses vis-à-vis customers. Nonetheless, in the absence of legislatively authorized antitrust immunity, horizontal agreements of all types are within the reach of the antitrust laws. Conduct by or towards labor is subject to the antitrust laws unless expressly permitted by legislation such as the Norris-LaGuardia Act of 1932, 29 U.S.C $\$ \$ 101-115$, which immunizes certain union activities from liability under the antitrust laws.
} 
wages and employment patterns across the high-tech sector would be a difficult and perhaps impossible task, even in the presence of some harm to a group of employees with certain specialized skills.

This is an interesting line of defense, for a number of reasons. For one thing, it begs the following question: If the agreements were unlikely to have had any effects at all, why did the firms bother to enter into them in the first place? In addition, there was evidence that showed that in some cases the parties not only entered into these agreements, but actively took steps to enforce them.

Whether the agreements were on balance pro-competitive or anti-competitive is a separate question - one that we discuss below. Revealed preference arguments, however, provide good reason for skepticism that the agreements were entered into with no expectation of their having any effect at all.

\subsubsection{Efficiencies?}

Non-compete agreements are not necessarily economically harmful and thus properly treated as illegal. They can, at times, be ancillary to achieving efficiencies from a joint venture. For example, if information about the quality of particular high-quality employees is conveyed to one's partner in the course of a collaborative activity, this may lead to greater competition for that employee than would exist absent the collaboration. The prospect of such an outcome may, at times, impede the effectiveness of a joint venture. Firms may be reluctant to assign their most valuable employees to a collaborative project, and in some instances this may even prevent efficient collaborations from taking place at all. In other words, non-compete agreements can be sensibly and efficiently ancillary to a pro-competitive collaboration.

The facts in this case did not support an ancillarity defense of the kind that antitrust law carves out from its prohibition against "naked" agreements not to compete. Although the defendants in this case at times engaged in legitimate collaborative projects with one another, under established antitrust law the no-cold-call solicit agreements were not properly ancillary to those collaborations. The defendants no-solicitation agreements were not, for example, tied to any specific collaboration. Nor were the agreements narrowly tailored to the scope of specific collaborations. The agreements extended to all employees at the firms, including those who had little or nothing to do with the collaborations, and were not limited by geography, job function, product group, or time period. Broad non-compete agreements, whether targeting labor markets or product markets, are not justified by general assertions that too much competition makes one a less desirable or attractive partner. Were the ancillarity defense to sweep that broadly, it might, for example, be presented as justification for an agreement between two firms not to compete against one another in any product market, even those where their rivalry greatly benefits consumers, since such an agreement could enhance mutual goodwill and thus lead to collaborations on some totally unrelated projects.

The lack of "reasonable necessity" for these broad agreements was demonstrated also by the fact that the defendants and other high-tech firms engaged in other substantial collaborations that included more narrowly focused hiring restrictions and for which there was no evidence of a resulting inefficiency. 


\section{Competition Advocacy}

The Division's economists have been unusually active this past year working with sister federal agencies on a variety of initiatives. Our economists have provided analysis of and input into, most especially, federal initiatives in the healthcare, financial services, insurance, telecommunications and agriculture industries. In the last, the Division and the USDA jointly sponsored an unprecedented series of workshops across the country. These addressed a range of economic issues that affected participants in, for example, the beef, chicken, and dairy industries. ${ }^{21}$

The Division also provided competitive analysis and filed formal comments in a matter before the Department of Transportation (DOT) that dealt with a proposed swap of airline takeoff and landing slots by two major U.S. airlines. A brief discussion of the competitive concerns that were conveyed in our analysis of that proposal follows.

\subsection{Slot Swaps: Delta and US Airways}

In late 2009, Delta and US Airways proposed a permanent exchange of more than 300 takeoff and landing slots (representing the rights to more than 150 daily round trips) at LaGuardia Airport (LGA) and Ronald Reagan Washington National Airport (DCA). The parties sought a waiver from a Federal Aviation Administration (FAA) order that prohibited the permanent transfer of LaGuardia slots. Under FAA regulations, it may grant a waiver if it finds the transfer to be "in the public interest." Economists at the Antitrust Division conducted an independent economic analysis of the proposed slot swap. The formal comments ${ }^{22}$ filed by the Department of Justice with the DOT drew heavily on EAG's analysis.

In its comments, the Justice Department supported the proposed DOT Order that would permit the slot transfers, subject to the condition that the carriers dispose of 14 pairs of slot interests at Reagan National and 20 pairs of slot interests at LaGuardia to "eligible new entrant and limited incumbent carriers." We offered recommendations also on the appropriate means for divesting these slots.

\subsubsection{Competitive Concerns}

The transaction raised two distinct competitive concerns. One was that it would harm consumers by reducing actual and potential competition between Delta and US Airways at DCA and LGA. A second was that the transaction would undermine competition by inhibiting entry by other carriers, especially low cost carriers (LCCs) at DCA and LGA.

\footnotetext{
21 See http://www.justice.gov/atr/public/workshops/ag2010/index.html.

22 See, Public Comments to the FAA. Notice of Petition for Waiver of the Terms of the Order Limiting Scheduled Operations at LaGuardia Airport and Solicitation of Comments on the Grant of Petition with Conditions (http://www.justice.gov/atr/public/comments/257463.pdf).
} 
LGA and DCA are two important, slot-controlled airports. Slot holdings at DCA and LGA are concentrated in the hands of the "legacy carriers", 23 principally US Airways and Delta. The transaction would have increased US Airways' share of slots at DCA from 44 to 54 percent and Delta's share at LGA from 24 percent to 49 percent.

A key competitive concern in the investigation was that the transaction would have reduced competition between Delta and US Airways on a number of routes at DCA and LGA, thereby harming consumers. In addition to serving their hubs and major focus cities, which is what other incumbent carriers at these airports do almost exclusively, Delta and US Airways also compete against one another in a number of "non-core" routes, and they are one another's most likely potential competitors on numerous routes at DCA and LGA. Much of this actual and potential competition between Delta and US Airways would have been lost as a result of the transaction.

The Division concluded that service from other New York or Washington area airports would not have fully offset the lost competition at DCA and LGA between the two carriers. Although other airports may be acceptable substitutes for some passengers (particularly for those price-sensitive passengers most willing to incur extra travel time to save money), competition among carriers specifically at LGA and DCA generates benefits for many others. Various pieces of evidence, including differences in average fares across area airports, the high values attached to slots, and carriers' efforts to protect these slots, all indicate that there is meaningful differentiation between LGA and DCA and other area airports.

The Division further concluded that the parties' transaction, as originally proposed, would have made LCC entry at the affected airports less likely, thereby depriving consumers of the lower fares that vigorous competition from LCCs would generate. ${ }^{24}$ In principle, limited or non-incumbent carriers, including LCCs, might be able to acquire slots in a secondary slot market (not all slots are currently held by the one or two dominant incumbents) or through FAA reallocation or mandated usage of under-utilized slots. In practice, however, slots rarely become available to these carriers through either method, especially in sufficient numbers to support entry at an efficient scale. Furthermore, the evidence indicates that incumbent carriers continue to hoard slots and use them sub-optimally, in part to keep them out of the hands of new entrants. As discussed in greater detail in our formal comments, there are a variety of commercial disincentives for large incumbents to sell or lease slots, and there are multiple ways by which large incumbents have resisted regulatory efforts to foster efficient slot allocation and usage. For example, while the FAA imposes a "use or lose" requirement for some slots that mandates that they be used eighty percent of the time over a two-month period, this rule does not in practice translate into slot usage patterns that replicate the outcome of competition. Incumbents instead tend to fly excessive frequencies (which increases slot utilization) with small planes (which reduces the cost of

\footnotetext{
23 Legacy carriers are incumbents that have been operating since long before the deregulation of the airline industry in the late 1970s and early 1980s and that tend to employ a hub-and-spoke system of flights.

24 Empirical work by EAG suggested that the presence of an LCC on a non-stop route reduces fares by roughly twenty-five percent. This is consistent with an extensive economic literature that shows the large effect of LCCs on fares, relative to effects caused by other classes of carriers. EAG's empirical work also suggested that airports with higher LCC penetration have much lower fares.
} 
a flight while still "using" the slot). In particular, we found that US airways and Delta operate significantly smaller aircraft at LGA and DCA than do the airlines eligible to purchase the divested slots. Assets are used in less efficient, less pro-consumer, ways than would result from greater entry and competition. The proposed swap, relative to likely "but for" scenarios, would have harmed consumers by making pro-competitive reallocations and usage patterns significantly less likely.

\subsubsection{Remedy}

Two issues arose in the crafting of an efficient remedy to the original slot swap proposal. One was to permit the carriers to achieve likely post-transaction efficiencies that might flow from increased slot holdings. The second was to help ensure that slots that were ordered to be divested as a condition of the swap be used by third parties to maintain competition otherwise eliminated.

The parties contended that the transaction would enable Delta to create a hub at LGA and to increase annual capacity at the airport by more than two million seats. They also argued that the transaction would result in US Airways' increasing annual capacity at DCA by one million seats. The Division expressed skepticism over the magnitude of any such efficiencies - given that an appropriate benchmark for measuring them was not necessarily the current pattern of usage (in particular, usage by the struggling US Airways at LGA), but instead the pattern of usage that was likely to obtain in the event that the swap were prohibited completely. The evidence also suggested that, even on the assumption that the transaction would increase capacity and traffic at the airports, the relatively modest slot divestiture proposed by the FAA was unlikely to interfere substantially with those benefits.

Finally, concerning the appropriate means for divesting slots, the Division recommended an option that would preserve the anonymity of potential buyers. ${ }^{25}$ This would make it more difficult for the divesting carriers to disfavor acquirers that are most likely to compete with them, even though such acquirers might generate the greatest consumer benefit from the use of the slots. The Division explicitly recognized that, under well-accepted economic theory, it could be argued that as long as transaction costs are low and secondary sales are permitted slots should be bought and sold until they are put to their highest-valued use. However, in the presence of market power, there is a divergence between the private and social value of a slot: A party with market power may purchase a slot to foreclose entry. Furthermore, the Division concluded that, in practice, a number of factors have inhibited efficiency-enhancing transfers of slots in the secondary market. Therefore, even with rules in place to prevent incumbents with market power from purchasing slots to impede entry, we were not confident that the secondary market would be sufficiently liquid to reallocate slots to the carriers who would put them to their socially highest-value use. ${ }^{26}$

\footnotetext{
25 The Division also suggested imposing limits on the pool of carriers that were deemed eligible to purchase the divested slots.

26 See Department of Transportation Final Decision, Notice on Petition for Waiver of the Terms of the Order Limiting Scheduled Operations at LaGuardia Airport (http://www.regulations.gov/search/Regs/ home.html\#documentDetail?R=0900006480aeb0a5).
} 


\section{Conclusions}

The coming year promises to present many new and interesting opportunities for Division economists to apply sound principles of microeconomic analysis to a wide range of business conduct and public policy. Opportunities to help devise, implement and respond to major changes in the health services and financial regulatory systems in the U.S., an increasingly integrated global economy, and a newly issued set of Horizontal Merger Guidelines are among the many future challenges that will make it an especially exciting time to be an economist in the business of antitrust enforcement.

Acknowledgments The authors would like to thank Erika Hamalainen for valuable assistance in preparing this manuscript. We also want to express our great appreciation to the EAG managers and many talented staff economists who performed outstanding work on the matters discussed herein: Robin Allen, Elizabeth Armington, William Drake, Wayne Dunham, Eric Emch, Nathan Goldstein, Nicholas Hill, Rene Kamita, Michael Klass, Robert Majure, Nathan Miller, William Nye, Lori Parcel, Oliver Richard, Michael Sandfort, Mary Schaffer, Jennifer Shanefelter, Jeffrey Wilder, Jeremy Verlinda, Gregory Werden, and Tor Winston.

Open Access This article is distributed under the terms of the Creative Commons Attribution Noncommercial License which permits any noncommercial use, distribution, and reproduction in any medium, provided the original author(s) and source are credited.

\section{References}

Miller, N., \& Osborne, M. (2010). Competition among spatially differentiated firms: An empirical model with an application to cement. EAG Discussion Paper, pp. 10-12.

Porter, R. \& Zona, D. (2009). Bidding, bid rigging, and school milk prices: Ohio v. Trauth (1994). In J. Kwoka, \& L. White (Eds.), Antitrust Revolution: Economics, Competition and Public Policy, 5th Ed. (pp. 329-350). New York: Oxford University Press.

Romeo, C. (2010). Filling out the instrument set in mixed logit demand systems for aggregate data. EAG Discussion Paper, pp. 10-13.

Shapiro, C. (2010). The 2010 horizontal merger guidelines: From Hedgehog to Fox in forty years. Antitrust Law Journal.

Werden, G. (2009). Essays in consumer welfare and competition policy. EAG Discussion Paper. 